16. Абросимов С.Н., Рыбин Б.И. Конструирование как творческая составляющая учебного процесса. // Проблемы качества графической подготовки студентов в техническом вузе: традиции и инновации. 2016. Т.1. С.143-149.

17. Абросимов С.Н., Рыбин Б.И. Элементы конструирования в учебном процессе по инженерной и компьютерной графике. В сборнике: Седьмые Уткинские чтения Труды международной научнотехнической конференции. 2016. С. 226-229.

18. Абросимов С.Н., Семенов В.А. Использование разработок по проектированию воздухоопорных конструкций в учебном процессе при геометро - графической подготовке технических специалистов. Тенденции развития науки и образования. 2018. № 44-1. С. 9-12.

19. Абросимов С.Н., Тихонов-Бугров Д.Е. Проектно-конструкторское обучение инженерной графике: вчера, сегодня, завтра. Геометрия и графика. 2016. Т.3 №3. С.47.

\title{
Абросимов С.Н., Глазунов К.О., Тихонов-Бугров Д.Е. К вопросу об использовании «проблемных заданий» в рамках базовой части курса «Инженерная и компьютерная графика»
}

Балтийский Государственный Технический Университет «ВОЕНМЕХ» (Россия, Санкт-Петербург)

doi: $10.18411 / \mathrm{j}-05-2021-214$

\section{Аннотация}

В работе рассмотрен один из приемов совершенствования учебного процесса по дисциплине «Инженерная и компьютерная графика» в техническом ВУЗе. Сегодня эта тема является актуальной, беспокоящая практически как всё педагогическое сообщество, так и работодателей. Авторами отмечается целесообразность введения в учебный процесс практических элементов инженерных конструкций и приёмов конструирования, усиливающих базовую часть инженерной и компьютерной графики.

Ключевые слова: инженерная и компьютерная графика, геометрическое моделирование, проблемные задания, конструирование.

\section{Abstract}

The paper considers one of the methods of improving the educational process in the discipline "Engineering and Computer Graphics" in a technical university. Today, this topic is relevant, worrisome almost as the entire pedagogical community and employers. The authors note the expediency of introducing practical elements of engineering structures and design techniques into the educational process that enhance the basic part of engineering and computer graphics.

Keywords: engineering and computer graphics, geometric modeling, problem tasks, design.

Одним из путей совершенствования учебного процесса в рамках дисциплины «Инженерная и компьютерная графика» является наполнения его отдельными творческими заданиями, включёнными в базовую часть курса [1-4]. Такие задания обрисовывают проблемы технического характера, требующие со стороны обучаемого проявления инициативы, поиска решений и более глубокого изучения материала в рамках инженерных знаний, т.е. работы не только с рекомендуемой литературой, но и обращаясь к другим источникам информации.

В настоящей разработке предпринята попытка расширить диапазон действий со стороны студентов при скицыровании изготовленных образцов техники (рис. 1), дополнив их элементами, повышающих надёжность и улучшающих технические характеристики изделий. 


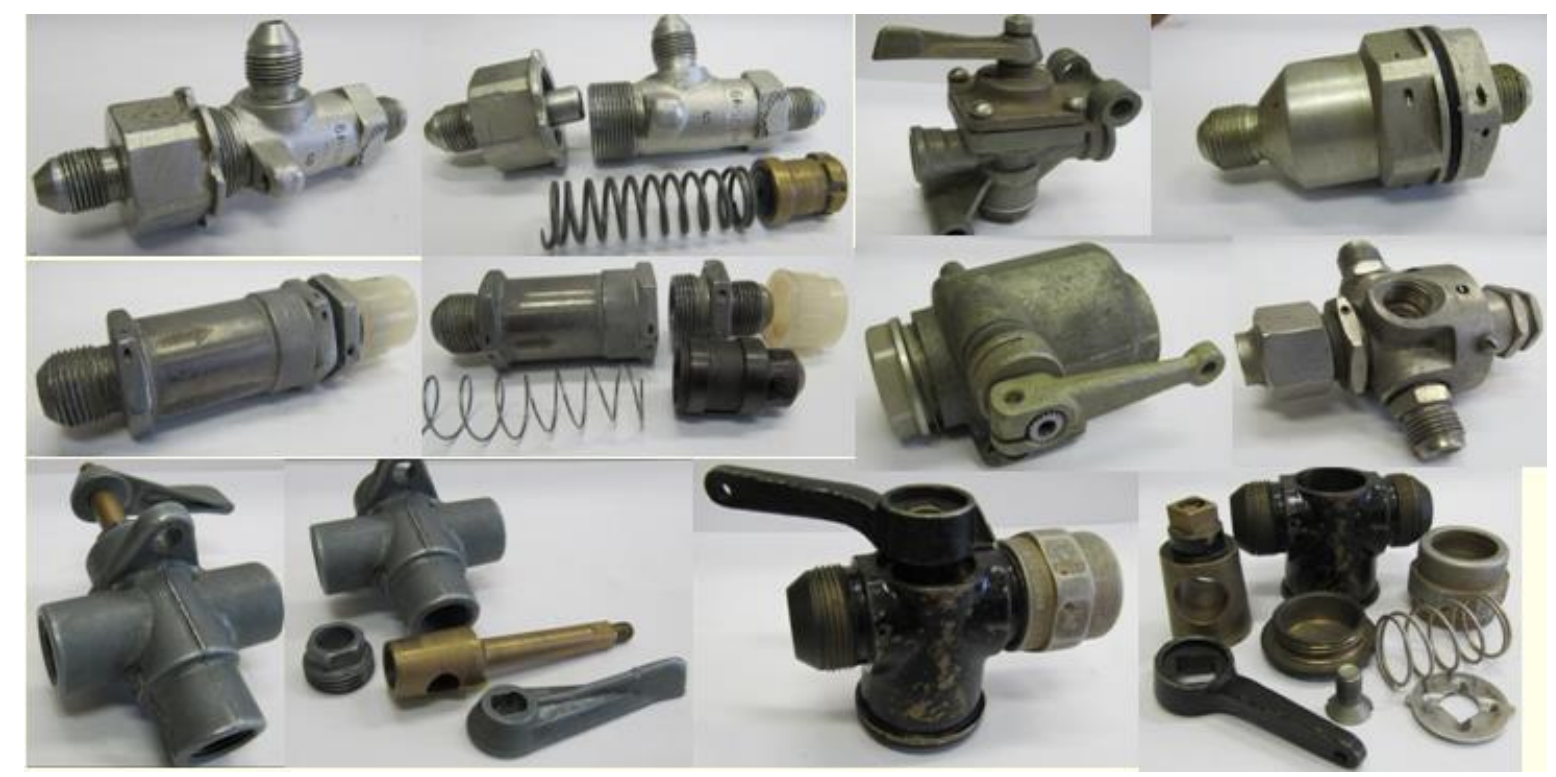

Рис. 1. Изготовленные образиы пневмогидроарматуры.

Базовой частью курса, предусмотренной учебным планом является выполнение:

комплекта рабочих чертежей на резьбовое соединение (чертежи двух резьбовых деталей и сборочного чертежа на их взаимное соединение с учетом соответствующих правил ЕСКД);

разработка комплекта рабочей документации на изготовленный образец техники виде элемента пневмогидроаппаратуры (вентиль, обратный клапан, регулирующее устройство и др.).

Поскольку детали являются готовыми изделиями, то их геометрические и технические характеристики наглядны и очевидны, остается только выполнить их изображения с размерной и другой информацией. Однако, известно, что резьбовые соединения под действием вибраций, изменений температуры окружающей среды, подвержены развинчиванию, что приводит к ухудшению прочности соединения, что недопустимо в работе изделия.

Чтобы исключить это нарушение в работе изделия, применяются различные стандартные способы стопорения резьбовых соединений. Эти способы представлены в соответствующей технической и учебной литературе и примеры приведены на рис.2.
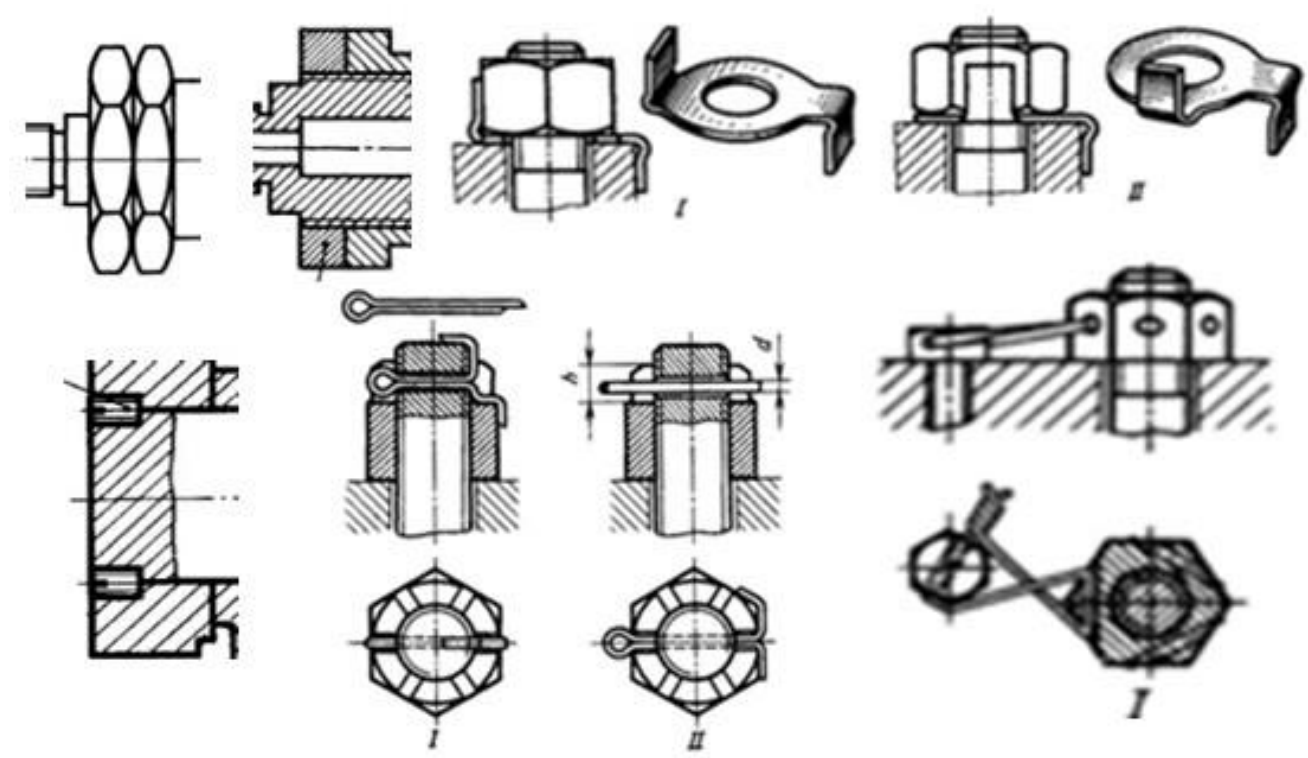

Рис.2. Используемые средства стопорения. 
Студентам предлагается самостоятельно с учетом конструктивных особенностей резьбовых деталей и их соединения выбрать способ стопорения резьбового соединения с внесением соответствующих изменений в конструкцию деталей.

Кроме этого, при скицировании изделий напрашиваются дополнительные технические решения, улучшающие пользовательские характеристики изделия (изменение параметров соединительных элементов, изменение их ориентации, придание отдельным составляющим изделия других геометрических форм, не влияющих на функциональность, изменение конструкций запорных органов предохранительных клапанов, и их типов, продумывание и конструкторская реализация вопросов собираемости и возможного ремонта) [5-8].

Особое место в проблемных заданиях занимает модификации элементов конструкции выполняемых в рамках разработки рабочей конструкторской документации по проектному чертежу (чертежу ВО). При этом обращается внимание на критический взгляд на имеющуюся конструкцию изделия с целью её совершенствования в рамках геометрического моделирования. Практически в каждое изделие можно внести изменения дизайнерского характера, в тоже время не изменяя основные функциональные характеристики. Это могут быть элементы крепления (рис.3), изменение габаритных размеров (рис.4), местоположения соединительных элементов и ряд других.
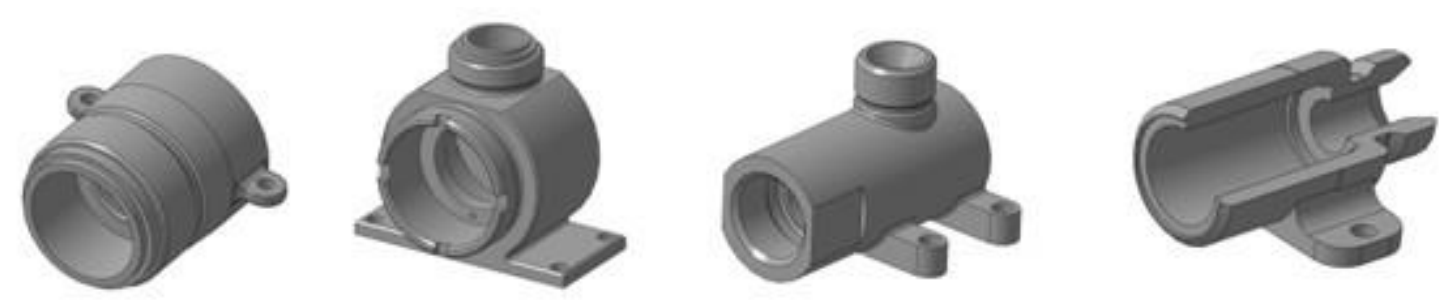

Рис.3. Модификация по элементам крепления.
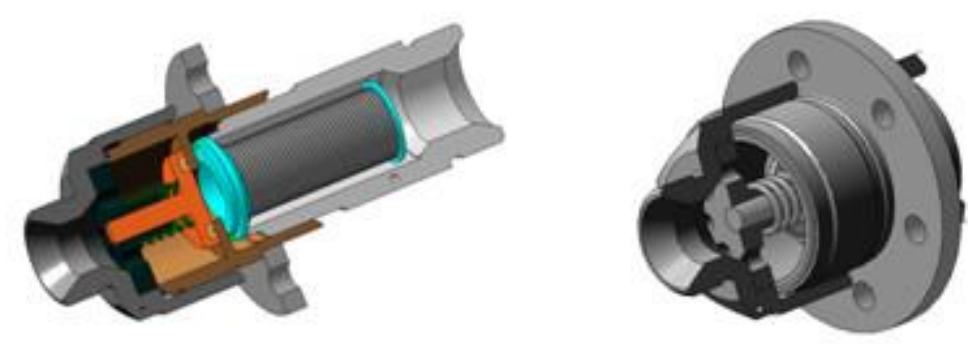

Рис.4. Модификаичи с учётом МЦХ.

Практическое использование графических пакетов позволяет достаточно оперативно перебирать возможные варианты изменения конструкций, опираясь на дополнительные возможности программных средств (например, МЦХ - массо центровочные характеристики и ряд других приложений) [9].

Всё в целом сказанное, позволяет расширять диапазон знаний будущих технических специалистов и развивать практические навыки работы с технической литературой, ориентированной на конкретные изделия.

$$
* * *
$$

1. Тихонов-Бугров Д.Е., Абросимов С.Н., Дюмин В.А. Базовые принципы преподавания инженерной и компьютерной графики будущим специалистам. Труды Международной конференции по компьютерной графики и зрению "Графикон". 2018. № 28. С. 389-392.

2. Абросимов С.Н., Тихонов-Бугров Д.Е. Проектно-конструкторское обучение инженерной графике: вчера, сегодня, завтра. Геометрия и графика. 2016. Т.3 №3. С.47. 
3. Вехтер Е.В., Сафьянникова В.И. Реализация проектного обучения при изучении дисциплины «Инженерная графика» // Современные проблемы науки и образования. - 2015. - №1-1.

4. Абросимов С.Н., Тихонов-Бугров Д.Е. О методических аспектах геометро - графической подготовки технических специалистов. Современное образование: содержание, технологии, качество. 2019. Т. 1. С. 90-92.

5. Абросимов С.Н., Рыбин Б.И. Конструирование как творческая составляющая учебного процесса. // Проблемы качества графической подготовки студентов в техническом вузе: традиции и инновации. 2016. Т.1. С.143-149.

6. Абросимов С.Н., Рыбин Б.И. Элементы конструирования в учебном процессе по инженерной и компьютерной графике. В сборнике: Седьмые Уткинские чтения Труды международной научнотехнической конференции. 2016. С. 226-229.

7. Орлов П.И. Основы конструирования: Справочно - методическое пособие. В 2-х кн. / Под ред. Н.П. Учаева - Изд. 3-е, испр. - М.: Машиностроение, 1988.

8. Анурьев В.И. Справочник конструктора-машиностроителя: В 3 т. / Под ред. И. Н. Жестковой.-8-е изд., перераб. и доп.- М.: Машиностроение, 2001. — ISBN 5-217-02962-5.

9. Абросимов С.Н. Геометрическое моделирование изделий машиностроения (Базовый уровень). Практическое пособие. Балт. гос. техн. ун.-т - СПб, 2020г.С.52

\section{Антохина B.А., Афонасова О.C. \\ Проявления фонетико-фонематического недоразвития речи у детей старшего дошкольного возраста с общим недоразвитием речи III и IV уровней ФГБОУ «Калужский государственный университет им. К.Э. Циолковского»} (Россия, Калуга)

doi: $10.18411 / \mathrm{lj}-05-2021-215$

\section{Аннотация}

В статье рассматриваются проявления фонетико-фонематического недоразвития речи у детей старшего дошкольного возраста с общим недоразвитием речи III и IV уровней. Обсуждаются направления коррекционной работы, связанной с преодолением нарушений фонетико-фонематического развития у данной категории детей.

Ключевые слова: фонетико-фонематическое недоразвитие речи, общее недоразвитие речи, старший дошкольный возраст, звукопроизношение, фонематическое восприятие, фонематические процессы.

\section{Abstract}

The article examines the manifestations of phonetic and phonemic speech underdevelopment in older preschool children with general speech underdevelopment of levels III and IV. The directions of correctional work related to overcoming violations of phonetic-phonemic development in this category of children are discussed.

Keywords: general speech underdevelopment, senior preschool age, sound pronunciation, phonemic perception, phonemic processes.

В последнее время нарушения фонетико-фонематического развития речи фиксируются у значительного количества детей, поступающих в школу. В основе становления всех сторон речи лежит именно звуковая материя языка, на ее базе складывается умение различать и воспроизводить лексико-грамматические категории, слова, фразы. В связи с этим фонетико-фонематические нарушения выступают в качестве серьезного фактора, препятствующего овладению всеми сторонами речи [9]. Сформированность звукопроизношения и фонематического восприятия является одним из базовых условий успешного усвоения школьной программы. Умения произносить и слышать в слове отдельные звуки, устанавливать их последовательность рассматриваются в специальных логопедических и лингвометодических исследованиях в качестве показателей готовности детей к обучению чтению и письму . 